\title{
Caracterização Molecular de Animais da raça Nelore utilizando Microssatélites e Genes Candidatos
}

\author{
Daniella Debenedetti Tambasco ${ }^{1}$, Maurício Mello de Alencar ${ }^{2}$, Luiz Lehmann Coutinho ${ }^{3}$, Antonio \\ Junqueira Tambascoㄹ, Marina Debenedetti Tambasco ${ }^{1}$, Luciana Correia de Almeida Regitano ${ }^{2}$
}

\begin{abstract}
RESUMO - No presente trabalho, 180 fêmeas da raça Nelore, provenientes de oito rebanhos, foram analisadas quanto aos marcadores microssatélites TEXAN15, BM1224 e CSFM50 e aos polimorfismos de comprimento de fragmentos de restrição (RFLP) nos locos Kcaseína, $\beta$-lactoglobulina e hormônio de crescimento $(\mathrm{GH})$. Com exceção de $\mathrm{GH}$, todos os marcadores foram polimórficos na amostra estudada. Os valores de heterozigosidade, diversidade gênica, conteúdo de informação polimórfica (PIC) e probabilidade de exclusão de paternidade (PE) foram estimados. Os maiores valores de PIC $(0,685)$ e PE $(0,521)$ foram obtidos para o marcador BM1224.
\end{abstract}

Palavras-chave: bovino, DNA, marcador, microssatélite, Nelore, RFLP

\section{Molecular Characterization of a Nellore Beef Cattle Sample Using Microsatellites and Candidate Genes}

\begin{abstract}
In the present work, 180 Nellore females from eight herds were analyzed for TEXAN15, BM1224 and CSFM50 microsatellites and for the restriction fragments polymorphism (RFLP) at the locos $\kappa$-casein, $\beta$-lactoglobulin and growth hormone (GH). Excepted for GH, all markers were polymorphic in the studied sample. The values of heterozigozity, gene diversity, polymorphic information content (PIC) and paternity exclusion probability (PE) were estimated. The highest PIC (0.685) and PE (0.521) values were obtained for microsatellite BM1224.
\end{abstract}

Key Words: bovine, DNA, marker, microsatellite, Nelore, RFLP

\section{Introdução}

Devido a sua importância econômica e cultural, estudos das relações genéticas entre rebanhos bovinos têm sido, historicamente, uma área ativa da sistemática biológica. A caracterização de determinada raça pode ser feita por suas propriedades fenotípicas, morfológicas e fisiológicas, origem, habitat, distribuição geográfica, produção e parâmetros genéticos (MOHAMMED, 1997; VALE FILHO et al., 1997; Del LAMA et al., 1996; e HERNANDEZ et al., 1997). A caracterização genética de populações, raças e espécies diferentes permite o estudo da variabilidade genética. O conhecimento da variabilidade, por sua vez, é fundamental para os programas de conservação genética de rebanhos em situação de risco (MACHUGH et al., 1994). Nesse contexto, marcadores moleculares têm sido amplamente utilizados, com a possibilidade de monitorar regiões do genoma, transcritas ou não, entre os quais podem-se destacar os polimorfismos de fragmentos de restrição (RFLP) e os marcadores do tipo microssatélite, altamente polimórficos, ambos obtidos pela técnica de PCR. Tais marcadores têm sido utilizados em estudos de caracterização de populações bovinas brasileiras. ROSA et al. (1997) caracterizaram animais da raça Nelore quanto aos marcadores RFLP de CSN3 ( $\kappa$-caseína), LGB ( $\beta$-lactoglobulina) e hormônio de crescimento $(\mathrm{GH})$ e quanto aos microssatélites IGFI, INRA006, CSFM50 e BM1224. Del LAMA e ZAGO (1996) e KEMENES (1996) investigaram a frequência dos alelos de $\kappa$-caseína e $\beta$-lactoglobulina em populações Nelore e Gir, e TAMBASCO (1998), em animais da raça Jersey.

A comparação de alelos de microssatélite entre raças bovinas tem sido utilizada na investigação de sua domesticação e migração e, conseqüentemente, de sua história evolutiva (LOFTUS et al., 1994; MACHUGH et al., 1997). Além disso, a caracterização genética pode ser utilizada

\footnotetext{
1 Departamento de Genética e Evolução - UFSCar, São Carlos - SP. E.mail: jtalhari @ terra.com.br; matamb @ terra.com.br

2 EMBRAPA - CPPSE, São Carlos, SP. E.mail: mauricio@ cppse.embrapa.br; tambasco@ zaz.com.br; luciana@cppse.embrapa.br

${ }^{3}$ Departamento de Produção Animal - ESALQ, Piracicaba - SP. E.mail: Ilcoutin@ carpa.ciagri.usp.br
} 
em estudos de relações entre espécies e gêneros correlatos (KEMP et al., 1995).

Vários programas de melhoramento utilizam informações de progênies, e seu sucesso depende, entre outros, da precisão na determinação das relações de parentesco, limitada a animais pertencentes à populações caracterizadas para os marcadores genéticos que se pretende utilizar (DODDS et al., 1996).

O delineamento de esquemas de cruzamentos que resultem em progênies de fenótipos mais desejáveis tem preocupado os geneticistas desde o início do século. Maior entendimento do padrão de variabilidade genética entre rebanhos poderá ser útil no desenvolvimento de programas de cruzamentos mais racionais (LOFTUS et al., 1994).

O objetivo deste trabalho foi caracterizar uma amostra de animais da raça Nelore quanto aos marcadores microssatélite TEXAN15, BM1224 e CSFM50 e os polimorfismos de tamanho de fragmentos de restrição CSN3, LGB e GH.

\section{Material e Métodos}

Foram analisadas 180 fêmeas da raça Nelore quanto aos marcadores microssatélite TEXAN15, BM1224 e CSFM50 e os polimorfismos de restrição do Hormônio de Crescimento (GH - AluI), CSN3 (Kcaseína - HinfI) e LGB ( $\beta$-lactoglobulina - HaeIII), amplificados pela técnica de PCR. O DNA genômico foi obtido a partir de células brancas de sangue periférico, pelo método de OLERUP e ZETTERQUIST (1992), adaptado por Regitano (dados não publicados).

\section{Condições da reação de PCR}

As reações de amplificação foram conduzidas em aparelho termociclador Perkin-Elmer, modelo PE2400. Cada reação foi constituída de aproximadamente 200 ng de DNA genômico, em solução de PCR (20 nM Tris-HCl, pH8,4; $50 \mathrm{mM} \mathrm{KCl}$ ), acrescida de 1,5 mM $\mathrm{MgCl}_{2}, 200 \mathrm{nM}$ de cada dNTP, $0,4 \mu \mathrm{M}$ de cada primer e 0,5 unidades de Taq DNA polimerase, em um volume final de $25 \mu \mathrm{l}$. Os marcadores utilizados estão descritos na Tabela 1. As sequiências microssatélite foram amplificadas segundo ciclos descritos por BISHOP et al. (1994).

Os fragmentos de restrição foram separados em géis de agarose de baixo ponto de fusão $3 \%$, contendo brometo de etídio a $0,67 \mu \mathrm{g} / \mathrm{ml}$. A eletroforese foi realizada em tampão Tris-borato-EDTA a $5 \mathrm{~V} / \mathrm{cm}$.

Os marcadores microssatélite TEXAN15 e
Tabela 1 - Descrição dos marcadores de DNA

Table 1 - Descriptions of the DNA markers

\begin{tabular}{|c|c|c|c|}
\hline $\begin{array}{l}\text { Marcador } \\
\text { Marker }\end{array}$ & $\begin{array}{l}\text { Tipo } \\
\text { Type }\end{array}$ & $\begin{array}{l}\text { Cromossomo } \\
\text { Chromosome }\end{array}$ & $\begin{array}{l}\text { Referência } \\
\text { Reference }\end{array}$ \\
\hline $\mathrm{CSN}^{1}{ }^{1}$ & RFLP $^{4}$ & $6 q 26-33$ & $\begin{array}{l}\text { MEDRANO e } \\
\text { CORDOVA, } 1990\end{array}$ \\
\hline $\mathrm{LGB}^{2}$ & RFLP & $11 q 28$ & RON et al., 1994 \\
\hline $\mathrm{GH}^{3}$ & RFLP & 19q17-qter & SCHLEE et al., 1994 \\
\hline BM1224 & $\mathrm{MS}^{5}$ & 4 & BISHOP et al., 1994 \\
\hline TEXAN15 & MS & 5 & BURNS et al., 1995 \\
\hline CSFM50 & MS & 2 & MOORE et al., 1994 \\
\hline
\end{tabular}

1 K-caseína, ${ }^{2} \mathrm{~B}$-lactoglobulina, ${ }^{3}$ Hormônio de crescimento, ${ }^{4}$ Polimorfismo de tamanho de fragmento de restrição, ${ }^{5}$ Microssatélite.

$1 \mathrm{~K}$-casein, ${ }^{2} \mathrm{~B}$-lactoglobulin, ${ }^{3}$ Growth hormone, ${ }^{4}$ Restriction fragment length polymorphism, ${ }^{5}$ Microsatellite.

BM1224 foram analisados em sequenciador automático A.L.F. (Pharmacia Biotech), capaz de detectar nucleotídeos ou fragmentos de DNA marcados com fluorescência. Os oligonucleotídeos complementares à fita anti-sense, denominado primer forward, foram marcados com fluoresceína na extremidade 5'. Os fragmentos amplificados do marcador microssatélite CSFM50 foram separados em géis de poliacrilamida $6,0 \%$ e analisados pelo método de coloração com prata (COMINCINI et al., 1995).

\section{Métodos estatísticos}

As freqüências alélicas e genotípicas em cada loco foram estimadas pela contagem alélica e dos diferentes genótipos, respectivamente, de acordo com WEIR (1996), para a população Nelore. A probabilidade de equilíbrio associada às frequiências genotípicas observadas foi obtida pelo teste exato de probabilidade, dada à ocorrência de alelos com frequiências muito baixas ou iguais a zero (GUO e THOMPSON, 1992). Foram calculadas as medidas heterozigosidade (H) e diversidade gênica (D), como medidas de variabilidade populacional (WEIR, 1996), bem como o conteúdo de polimorfismo informativo (PIC) (BOTSTEIN et al., 1980) e a probabilidade de exclusão (PE), de acordo com DODDS et al. (1996).

\section{Resultados e Discussão}

As freqüências alélicas e os valores de H, D, PIC e PE estão sumarizados nas Tabelas 2 e 3 , respectivamente. Sendo o valor $\mathrm{H}$ uma medida de variabilidade que traduz a heterozigosidade observada, e o valor de $\mathrm{D}$, uma medida de variabilidade que traduz a 
1046 Rev. bras. zootec.

heterozigosidade esperada, maior discrepância destes parâmetros para determinado loco reflete o desequilíbrio genotípico da amostra. O valor de PIC foi calculado com o objetivo de avaliar cada loco quanto ao seu grau de importância em estudos de segregação. $\mathrm{O}$ parâmetro PE para um marcador reflete sua probabilidade de excluir a paternidade de um macho qualquer da população em relação a um par mãe-filho escolhido ao acaso (DODDS et al., 1996).

O loco GH apresentou-se monomórfico, sendo todos os animais homozigotos LL. A fixação do alelo L em raças zebuínas foi verificada em outros rebanhos do Brasil (ROSA et al., 1996; KEMENES et al., 1999). MITRA et al. (1995) observaram o alelo $\mathrm{V}$ em animais Sahival na Índia, com frequência de 0,04. A baixa frequência desse alelo em zebuínos pode explicar o monorfismo observado na população Nelore estudada. A frequência do alelo $\mathrm{V}$ apresenta maior variação entre populações taurinas. DeNise (1996 $\left.{ }^{1}\right)$ observou o alelo $\mathrm{V}$ com frequiências de 0,$47 ; 0,35 ; 0,27$; 0,26; 0,24; e 0,09 em animais das raças Gelbvieh, Hereford, Simmental, Angus, Limousin e Holstein, respectivamente. SCHLEE et al. (1994) obtiveram resultados similares em animais Simmental $(0,29)$. REGITANO et al. (1999) verificaram frequência de 0,26 do alelo $\mathrm{V}$ em animais da raça Charolesa. Em 214 animais da raça Friesian, GROCHOWSKA et al. (1999) verificaram freqüência de 0,31 do mesmo alelo.

Os locos $\kappa$-caseína, TEXAN15 e CSFM50 encontraram-se em equilíbrio de Hardy Weinberg ( $\mathrm{P}=1,0000$ e 0,0058 e 0,0388 , respectivamente), como mostram também os valores estimados de $\mathrm{H}$ e D para esses locos (Tabela 3). As freqüências observadas dos alelos de $\kappa$-caseína e $\beta$-lactoglobulina foram semelhantes às encontradas por Del LAMA e ZAGO (1996), KEMENES (1996) e ROSA (1997) em animais da raça Nelore. $\mathrm{O}$ alelo mais freqüente para o loco BM1224 foi o 4, correspondente ao fragmento de 177 pares de bases, seguido dos alelos $2,8,1$ e 6 , nesta ordem. Os alelos $-3,-1,3,7$ e 11 foram observados com baixa freqüência. Em contraste, ROSA (1997) e MERZEL et al. (1998) verificaram o predomínio do alelo 2 nos animais Nelore estudados, semelhança esta devida, provavelmente, à origem comum de seus rebanhos. Para o loco microssatélite TEXAN15, o alelo mais freqüente foi o 8 , correspondente ao fragmento de 203 pares de bases, como verificado por MERZEL et al. (1998), seguido dos alelos 6 e -1. Os alelos 7, 3, 2, 5, 1 e -2 foram observados em baixa frequência. Esse marcador encontra-se, segundo Taylor $\left(1998^{2}\right)$, a 7,7 Centimorgans do microssatélite IGF-I. Este marcador, por sua vez, foi associado às características de pesos ao nascimento, à desmama e a um ano de idade em animais da raça Hereford (MOODY et al., 1996). Para o microssatélite CSFM50, foram observados os alelos 3, 4, 6, 7 e 8, correspondentes aos fragmentos de 178, 176, 172, 170 e 168 pares de bases. O mais frequiente foi o 6 , seguido dos alelos 8, 4, 7 e 3 . ROSA et al. (1996) verificaram, em Nelore, a maior frequência do alelo 8, seguido dos alelos 4, 6, 7 e 3 . Esse microssatélite está localizado em uma região do cromossomo 2, que foi associada a características de peso da desmama até a maturidade em bovinos (DAVIS e TAYLOR, 1995). MERZEL et al. (1998) não observaram diferença significativa das freqüências dos alelos de CSFM50 em animais controle e selecionados para ganho de peso. Os autores verificaram, nos animais controle, a maior frequência do alelo 6 , seguido dos

Tabela 2 - Freqüências alélicas estimadas e erro-padrão (EP) das estimativas

Table 2 - Allelic frequencies estimated and standard error (SE)

\begin{tabular}{lrr}
\hline Loco & $\begin{array}{c}\text { Alelos } \\
\text { Locus }\end{array}$ & $\begin{array}{c}\text { Frequência } \pm \text { EP } \\
\text { Frequence } \pm S E\end{array}$ \\
\hline CSN3 & $\mathrm{A}$ & $0,944 \pm 0,012$ \\
LGB & $\mathrm{B}$ & $0,066 \pm 0,012$ \\
& $\mathrm{~A}$ & $0,239 \pm 0,022$ \\
GH & $\mathrm{B}$ & $0,761 \pm 0,022$ \\
& $\mathrm{~L}$ & 1,000 \\
BM1224 & $4(177)$ & $0,375 \pm 0,025$ \\
& $2(181)$ & $0,322 \pm 0,025$ \\
& $8(169)$ & $0,133 \pm 0,018$ \\
& $1(183)$ & $0,089 \pm 0,015$ \\
& $6(173)$ & $0,047 \pm 0,011$ \\
TEXAN15 & outros & 0,034 \\
& $8(203)$ & $0,606 \pm 0,026$ \\
& $6(207)$ & $0,164 \pm 0,019$ \\
& $-1(219)$ & $0,122 \pm 0,017$ \\
CSFM50 & outros & 0,108 \\
& $6(172)$ & $0,379 \pm 0,026$ \\
& $8(168)$ & $0,342 \pm 0,025$ \\
1 Themicrosatellite allelelength, in basepairs, is indicated between parenthesis.
\end{tabular}

\footnotetext{
$\overline{1}$ DeNise, S. University of Arizona. Comunicação pessoal, 1996.

2 Taylor, J.F. Texas A \& M University. Comunicação pessoal, 1998.
} 
TAMBASCO et al.

alelos 4, 8 e 7, e nos animais selecionados a predominância do alelo 8 , seguido dos alelos 6,4 e 7 .

Foi observada ausência de equilíbrio genotípico nos locos $\beta$-lactoglobulina $(\mathrm{P}<0,001)$ e $\mathrm{BM} 1224$ $(\mathrm{P}<0,001)$, caracterizada, em ambos os casos, por excesso de homozigotos. Algumas das condições que podem conduzir ao excesso de homozigotos são a endogamia, seleção ou ainda a presença de alelos nulos. No entanto, a endogamia deveria afetar todos os locos. A associação do polimorfismo do loco da $\beta$-lactoglobulina com características de produção não é ainda clara (OJALA et al., 1997), não sendo possível afirmar que a variação encontrada seja resultante de seleção. Entretanto, não existem relatos de alelos nulos para esse marcador. O excesso de homozigotos observado para o loco microssatélite BM1224 pode estar relacionado à presença de alelos nulos, ou seja, à não amplificação de determinado alelo, que leva a um falso genótipo homozigoto. Essa hipótese é ainda reforçada por dados de segregação dos alelos nessa população (Regitano, dados não publicados). Além de análises de segregação, a técnica de PCR quantitativa poderia auxiliar na investigação sobre alelos nulos. GLOWATZKIMULLIS et al. (1995) destacaram a problemática dos alelos nulos em estudos de paternidade. Em casos de exclusão baseados em apenas um microssatélite, deve ser dada especial atenção se a prole e os parentais são homozigotos, a fim de evitar um falso diagnóstico.

Os valores de H, D e PIC para o loco $\beta$-lactoglobulina foram 0,$244 ; 0,365$; e 0,298 e para o loco K-caseína, 0,$111 ; 0,105$; e 0,101 , respectivamente, menores que os observados por ROSA (1997). Para o loco GH, esses parâmetros tiveram valores iguais a zero, devido ao monomorfismo observado. Os valores de PIC encontrados para os cinco marcadores polimórficos estão de acordo com o esperado. Marcadores dialélicos possuem menor conteúdo de polimorfismo informativo que marcadores multialélicos. Dentre esses últimos, o que apresentou maior PIC foi o BM1224, apesar do excesso de homozigotos encontrado neste loco. Este resultado mostra que o parâmetro não deve ser considerado isoladamente, pois a presença de alelos nulos reduziria sua utilidade em análises de ligação.

Os marcadores microssatélite apresentaram maior $\mathrm{PE}$, como esperado para marcadores altamente polimórficos, tendo sido 0,$521 ; 0,389$; e 0,466 para os locos BM1224, TEXAN15 e CSFM50, respectivamente. Em contraste, para os marcadores RFLP CSN3 e LGB, foram observados os valores 0,051 e 0,165 . O loco GH obteve valor zero, devido ao monomorfismo observado na presente população (Tabela 3). Apesar de terem sido observados valores satisfatórios de PE em três dos seis marcadores analisados, a probabilidade de exclusão combinada (PEC) foi 0,876, abaixo do valor ideal $(0,99)$. ROSA et al. (1997) verificaram valores de PE maiores que os encontrados no presente trabalho, para os locos CSN3, LGB, CSFM50 e BM1224 $(0,0731 ; 0,1759 ; 0,5077 ;$ e 0,4406$)$.

Apesar das diferenças entre as técnicas de coloração com prata e sequenciador automático utilizadas, ambas mostraram-se eficientes na identificação dos genótipos

Tabela 3 - Número de alelos, estimativas de diversidade gênica (D), heterozigosidade $(H)$, conteúdo de polimorfismo informativo (PIC) e probabilidade de exclusão (PE)

Table 3 - Allele number, genetic diversity $(D)$, heterozigozity $(H)$, polymorphism informative content $(P I C)$ and exclusion probability (PE)

\begin{tabular}{lccccc}
\hline $\begin{array}{l}\text { Marcadores } \\
\text { Markers }\end{array}$ & $\begin{array}{l}\text { Número de alelos } \\
\text { Number of alleles }\end{array}$ & $\mathrm{D}$ & $\mathrm{H}$ & $\mathrm{PIC}$ & $\mathrm{PE}$ \\
\hline CSN3 & 2 & 0,105 & 0,111 & 0,101 & 0,051 \\
LGB & 2 & 0,365 & 0,244 & 0,298 & 0,165 \\
GH & 1 & 0,000 & 0,000 & - & - \\
BM1224 & 10 & 0,729 & 0,311 & 0,685 & 0,521 \\
TEXAN15 & 9 & 0,589 & 0,577 & 0,554 & 0,389 \\
CSFM50 & 5 & 0,661 & 0,669 & 0,641 & 0,466 \\
Média (EP) ${ }^{1}$ & 4,83 & 0,413 & 0,318 & - & $0,876^{2}$ \\
Mean (SE) & $(1,58)$ & $(0,126)$ & $(0,106)$ & & \\
\hline
\end{tabular}

1 Erro-padrão da média.

2 Probabilidade de exclusão combinada (RON et al., 1996).

1 Standard error of mean.

2 Combined exclusion probability (RON et al., 1996). 
1048 Rev. bras. zootec.

de microssatélite. O método de análise em sequenciador automático caracterizou-se principalmente pela eficiência e rapidez na identificação de genótipos. No entanto, a mesma sensibilidade foi alcançada com a utilização da coloração com prata, com menor custo, embora com maior tempo despendido.

\section{Conclusões}

As freqüências alélicas para os marcadores BM1224 e CSFM50 diferem das descritas para outras amostras da raça Nelore, confirmando a necessidade de caracterização de diferentes rebanhos de uma raça na determinação de frequiências alélicas.

Os valores de PIC e PE demonstram a superioridade dos marcadores microssatélites para o mapeamento genético e análise de parentesco. Para aplicação em investigações de parentesco, maior número de marcadores seria necessário para atingir os valores ideais desses parâmetros. Além disso, para essas aplicações, tais marcadores devem ser investigados quanto à ocorrência de alelos nulos.

\section{Referências Bibliográficas}

BISHOP, M.D., KAPPES, S.M., KEELE, J.W. et al. 1994. A genetic linkage map for cattle. Genetics, 136:619-639.

BOTSTEIN, D., WHITE, R.L., SKOLNICK, M. et al. 1980. Construction of a genetic linkage map in man using restriction fragment length polymorphisms. Am. J.Hum. Genet., 32:314-331.

BURNS, B.M., TAYLOR. J.F., HERRING, A.D. et al. 1995. Bovine microsatellite dinucleotide repeat polymorphisms at the TEXAN11, TEXAN12, TEXAN13, TEXAN14 and TEXAN15 loci. Anim. Genet., 26:201-202.

COMINCINI, S., LEONE, P., REDAELLI, L. et al. 1995. Characterization of bovine microsatellites by silver staining. J. Anim. Breed. Genet., 112:415-420.

DAVIS, S.K., TAYLOR, J.F., 1995. Mechanisms of genetic control of beef carcass merit traits. Research project summary outline - Interim report. Texas A \& M University, 1995. 10p.

DEL LAMA. S.N., DEL LAMA, M.A., MESTRINER, M.A. et al. 1996. Esterase D polymorphism and partial characterization of red blood cell esterases in cattle and buffalo populations. Braz. J. Genet., 19:243-248.

DEL LAMA, S.N., ZAGO, M.A. 1996. Identification of the $\kappa$-casein and $\beta$-lactoglobulin genotypes in Brazilian Bos indicus and Bubalus bubalis populations. Braz. J. Genet., 19:73-77.

DODDS, K.G., TATE, M.L., McEWAN, J.C. et al. 1996. Exclusion probabilities for pedigree testing farm animals. Theor. Appl. Genet., 92:966-975.

GLOWATZKI-MULLIS, M-L., GAILLARD, C., WIGGER, G. et al. 1995. Microsatellite-based parentage control in cattle. Anim. Genet., 26:7-12.

GROCHOWSKA, R., ZWIERZCHOWSKI, L., SNOCHOWSKI, M. et al. 1999. Stimulated growth hormone $(\mathrm{GH})$ release in Friesian cattle with respect to GH genotypes. Reprod. Nutr. Dev., 39:171-180.
GUO, S.W., THOMPSON, E.A. 1992. Performing the exact test of hardy-weinberg proportion for multiple alleles. Biometrics, 48:361-372.

HERNANDEZ, J., BENEDITO, J.L., CASTILlO, C. et al. 1997. Use of blood parameters as ethnic characteristics in cattle breeds. Archiv. Fuer. Tierzucht, 40:521-533.

KEMENES, P.A. Quantificação das frequências dos alelos " $A$ " $e$ " $B$ " dos genes de kappa -caseína e $\beta$-lactoglobulina em algumas raças bovinas. Piracicaba, SP: ESALQ, 1996. 85p. Dissertação (Mestrado em Zootecnia) - Escola Superior de Agricultura "Luiz de Queiroz"/Universidade de São Paulo, 1996

KEMENES, P.A., REGITANO, L.C.A., ROSA, A.J.M. et al. 1999. K-Casein, B-lactoglobulin and growth hormone allele frequencies and genetic distances in Nelore, Gyr, Guzera, Caracu, Charolais, Canchim and Santa Gertrudis cattle. Genet. Mol. Biol., in press.

KEMP, E.J., HISHIDA, O., WAMBUGU, J. et al. 1995. A panel of polymorphic bovine, ovine and caprine microsatellite markers. Anim. Genet., 26:299-306.

LOFTUS, R.T., MacHUGH, D.E., BRADLEY, D.G. et al. 1994. Evidence for two independent domestications of cattle. Proc. Natl. Acad. Sci. USA, 91: 2757-2761.

MACHUGH, D.E., LOFTUS, R.T., BRADLEY, D.G. et al. 1994. Microsatellite DNA variation within and among European cattle breeds. Proc. R. Soc. Lond. B., 256:25-31.

MACHUGH, D.E., SHRIVER, M.D., LOFTUS, R.T. et al. 1997. Microsatellite DNA Variation and the Evolution, Domestication and Phylogeography of Taurine and Zebu Cattle (Bos taurus and Bos indicus). Genetics, 146:1071-1086.

MEDRANO, J.F., AGUILAR-CORDOVA, E. 1990. Genotyping of bovine kappa-casein loci following DNA sequence amplification. Bio/Technology, 8:144-146.

MERZEL, M., ETCHEGARAY, M.A.L., SILVA, N.A. et al. Changes in allelic frequency of eight microsatellites in a Nelore herd selected for weight gain. In: CONGRESSO NACIONAL DE GENÉTICA, 44, 1998, Águas de Lindóia. Anais... Ribeirão Preto: Sociedade Brasileira de Genética, 1998. p.91.

MITRA, A., SCHLEE, P., BALAKRISHNAN, C.R. et al. 1995. Polymorphisms at growth-hormone and prolactin loci in Indian cattle and buffalo. J. Anim. Breeding Genet., 112:71-74.

MOHAMMED, T.A. 1997. Phenotypic characterization of the Saudi Arabian Hassawi cattle breed. Anim. Genet. Res. Inf., 21:35-42.

MOODY, D.E., POMP, D., NEWMAN, S. et al. 1996 Characterization of DNA polymorphisms in three populations of Hereford cattle and their associations with growth and maternal EPD in line 1 Herefords. J. Anim. Sci., 74:1784-1793.

MOORE, S.S., BYRNE, K., BERGER, K.T. et al. 1994. Characterization of 65 bovine microsatellites. Mamm. Genome, 5: 84-90.

OJALA, M., FAMULA, T.R., MEDRANO, J.F. 1997. Effects of milk protein genotypes on the variation for milk production traits of Holstein and Jersey cows in California. J. Dairy Sci., 80:1776-1785.

OLERUP, O., ZETTERQUIST, H. 1992. HLA-DR typing by PCR amplification with sequence-specific primers (PCRSSCP) in 2 hours: An alternative to serological DR typing in clinical practice including donor-recipient matching in cadaveric transplantation. Tissue Antigens, 39: 225-235. 
TAMBASCO et al.

REGITANO, L.C.A., AZEVEDO, J.L., VENCOVSKY, R. et al. 1999. Selection for breed-specific growth hormone and IGFI alleles in a synthetic beef cattle cross (Canchim). Genet. Mol. Biol. (in press).

RON, M., YOFFE, O., EZRA, E. et al. 1994. Determination of effects of milk protein genotyping on production traits of Israeli Holstein. J. Dairy Sci., 77:1106-1113.

RON, M., BLANC, Y., BAND, M. et al. 1996. Misindetification rate in the Israeli dairy cattle population and its implications for genetic improvment. J. Dairy Sci., 79:676-681.

ROSA, A.J.M., REGITANO, L.C.A, MERZEL, M. et al. Polymorphism of growth hormone, microsatellite IGF-I and association with feedlot performance in Nelore cattle. In: CONGRESSO NACIONAL DE GENÉTICA, 42, 1996, Caxambú. Anais... Ribeirão Preto: Sociedade Brasileira de Genética, 1996, p.298.

ROSA, A.J.M. Caracterização da raça Nelore e teste de paternidade pormarcadores moleculares. Piracicaba, SP: ESALQ, 1997. 114p. Dissertação (Mestrado em Zootecnia) - Escola Superior de Agricultura “Luiz de Queiroz”/Universidade de São Paulo, 1997.
SCHLEE, P, GRAML, R., SCHALLENBERGER, E. et al. 1994. Growth hormone and insuline-like growth factor I concentrations in bulls of various growth hormone genotypes. Theor. Appl. Genet., 88:497-500.

TAMBASCO, M.D. Detecção de polimorfismo dos genes de kappa-caseína e beta-lactoglobulina em animais da raça Jersey. São Carlos, SP: UFSCar, 1998. 36p. Monografia de Graduação - Universidade Federal de São Carlos.

VALE FILHO, V.R., BERGMANN, J.A.G., ANDRADE, V.J. et al. 1997. Andrologic characterization of Nelore bulls, selected for the first breed season. Rev. Bras. Reprod. Anim., 21:42-44.

WEIR, B.S. 1996. Genetic data analysis: methods for discret population genetic data. 2.ed. Massachusetts: Sinauer Associates. 445p.

Recebido em: 20/07/1999

Aceito em: 26/11/1999 